\title{
Characterization and Differentiation of Chicken Mycoplasma Isolates Using 16S-23S Intergenic Spacer Region Sequencing
}

\section{-Author(s)}

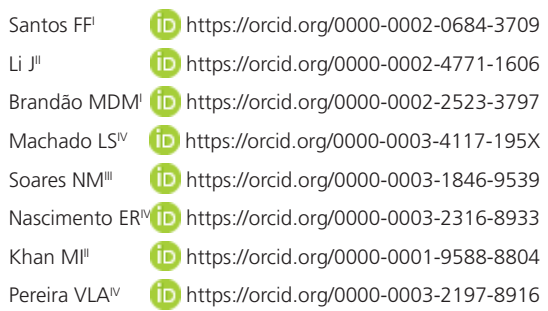

Instituto Federal de Educacao Ciencia e Tecnologia do Amazonas - CMZL - Medicina Veterinária Av. Cosme Ferreira, 8.045 Gilberto Mestrinho, Manaus, AM, 69086-475, Brazil

" University of Connecticut - Department of Pathobiology and veterinary Science - 61 North Eagleville Road, Unit-3089, Storrs, Connecticut 06269, United States.

III Inst. Biologico - CAPTAA - Av Gaspar Ricardo, 1700 Bastos-SP, Bastos, São Paulo 17690000, Brazil.

Iv Universidade Federal Fluminense Ringgold standard institution - Departamento de Saúde Veterinária Coletiva e Saúde Pública - Rua Vital Brasil Filho, 64, Niteroi, Rio de Janeiro 24230-340, Brazil.

\section{Mail Address}

Corresponding author e-mail address Felipe Faccini dos Santos

Instituto Federal do Amazonas, Medicina Veterinária, Campus Manaus Zona Leste, Amazonas, Brazil

Phone: +5592981176402

E-mail: felipefaccini@hotmail.com

\section{aKeywords}

Mycoplasma gallinaceum, Mycoplasma pullorum, Mycoplasma gallisepticum, intergenic spacer region, 16S-23S.

\section{ABSTRACT}

The objective of this study was to identify the species and characterize the genetic relationships among mycoplasma isolates from commercial layer hen flocks using 16S-23S rDNA intergenic spacer region (IGSR) sequencing. Twenty-one isolates were obtained from samples collected from commercial layer flocks in four Brazilian states: São Paulo, Minas Gerais, Rio de Janeiro and Espírito Santo. The isolates were recovered from the São Paulo, Rio de Janeiro and Espírito Santo states. Eleven isolates were originated from tracheal swabs, five from shell gland swabs and five from ovary fragment collection. The 16S-23S rDNA IGSR of isolates were amplified by PCR, and the obtained products were subsequently sequenced. The consensus of each isolate was compared to the available sequences using Nucleotide BLAST ${ }^{\circledR}$ to determine the mycoplasma species. A phylogenetic analysis of the Mycoplasma gallisepticum (MG) sequences was performed. Pairwise analyses showed homologies of $99 \%$ to $100 \%$ with the previously characterized sequences listed in GenBank $^{\circledR}$. Four Mycoplasma gallinaceum were isolated from three flocks and seven $M$. pullorum isolates were obtained from a single flock. The other 10 isolates were all identified as MG and were obtained from four flocks. The 16S-23S rDNA IGSR sequencing was a good method to identify Mycoplasma species isolated from field samples, providing fast and reliable results at relatively low costs. The results were also satisfactory for the single-locus sequence typing of MG isolates.

\section{INTRODUCTION}

Mycoplasma infections are highly prevalent among poultry flocks, and three species are considered to be pathogenic: Mycoplasma gallisepticum (MG), Mycoplasma synoviae (MS) and Mycoplasma meleagridis (MM). The economic losses attributed to mycoplasmosis are due to decreases in egg production and quality, poor hatchability, poor feed efficiency, high mortality rates and high carcass condemnation rates on slaughter (Kleven, 2008; Nascimento et al., 2005; Nascimento; Pereira, 2009). These microorganisms prefer the mucous and serous membranes of birds, causing respiratory, joint and urogenital pathologies. There are several strains of MG, MS and MM, which are phenotypic and genotypically different, that have diverse degrees of pathogenicity, virulence and immunogenicity (Kleven, 2008; Nascimento et al., 2005). The transmission of mycoplasmas can occur horizontally by aerosols; by sexual contact or artificial insemination; by direct contact with contaminated birds and indirect contact through people, other animals, food, water and equipment; or by vertical egg transmission (Kleven, 2008; Nascimento \& Pereira, 2009). In addition to the notably pathogenic mycoplasma, another 20 species are also known to infect birds (Kleven, 2008). These species are regarded as nonpathogenic species; however, some cases have been reported in 
Santos FF, Li J, Brandão MDM, Machado LS, Soares NM,

Nascimento ER, Khan M, Pereira VLA
Characterization and Differentiation of Chicken Mycoplasma Isolates Using 16S-23S Intergenic Spacer Region Sequencing which these species have caused diseases (Ganapathy et al., 1998; Kleven et al., 1978; Yagihashi et al., 1993; Moalic et al., 1997; Gomes, 2013; Silva et al., 2014).

The identification of Mycoplasma species using conventional techniques can be laborious and complex, requiring the use of biochemical and serological tests, with specific serum for each species. PCR is widely used for identification of pathogenic mycoplasmas, such as MG (Nascimento et al., 1991; García et al., 2005) and MS (Lauerman et al., 1998; Hong et al., 2004). For more rapid results, multiplex PCR is also available (Wang et al., 1997; Fraga et al., 2013). However, identification of isolates other than pathogenic species in not practical using regular PCR.

Recently, sequencing became more accessible for smaller facilities and with lower costs, thus can be used not only for research, but also in a regular basis by diagnostic laboratories. Ferguson et al. (2005) described a method with high discriminatory power amongst MG isolates by sequencing four regions of the bacterium that encode surface proteins. Subsequently, Raviv et al. (2007) obtained similar results by sequencing the 16S-23S rDNA intergenic spacer region, using as a single-locus sequence typing (SLST) tool for MG isolate differentiation in diagnostic cases and epizootiological studies. Using the same method, Ramírez et al. (2008) found that the 16S-23S rDNA intergenic spacer regions (IGSR) of avian mycoplasmas could be used to differentiate species because this region of the DNA has low inter-species homology, with a maximum percent of homology of $90.5 \%$ and a minimum of $7.9 \%$.

The objective of this study was to identify the species and characterize the genetic relationships among mycoplasma isolates from commercial layer hen flocks using a 16S-23S rDNA IGSR sequencing method.

\section{MATERIAL AND METHODS}

Samples were obtained from commercial layer flocks in four Brazilian states. The number of flocks sampled were five in São Paulo and Minas Gerais, two in at Rio de Janeiro and four in at Espírito Santo. From each flock, five birds were necropsied to obtain swabs from trachea, ovary and shell gland. All animal collection procedures were approved by the Ethics Committee on the Use of Animals of the Universidade Federal Fluminense under number 199, dated May 17, 2012. Isolation of mycoplasmas was performed using Frey medium (Frey et al., 1968) in agar and broth. Samples were incubated until 21 days, when chance in color and formation of egg-shaped colonies in agar were identified for positive samples.
DNA was extracted from $1 \mathrm{~mL}$ of media that showed mycoplasma growth by a color change using the phenol-chloroform method (SAMBROOK; FRITSCH, 1989). The 16S-23S rDNA IGSR of the isolates were amplified by $P C R$, as described by Ramírez et al. (2008), using the forward primer 5'-CGT TCT CGG GTC TTG TAC AC-3' and the reverse primer 5'- CGC AGG TTT GCA CGT CCT TCA TCG-3'. Sequencing was conducted at Fundação Oswaldo Cruz, RJ, Brazil, and the sequence was determined for each strand of DNA using an Applied Biosystems 3730xl DNA Analyzer. The resulting chromatograms were examined, and the forward and reverse complimented sequences of all isolates were compared to produce a consensus sequence using Lasergene SeqMan software (Version 7.2.1; DNASTAR, Australia).

The consensus of each isolate was compared to those available in GenBank $®$ using Nucleotide BLAST $®$ software (NCBI, 2017) to determine the mycoplasma species. The samples used for MG phylogeny included Brazilian isolates obtained by Couto et al. (2015) in Minas Gerais state, Brazil, with the following accession numbers: KJ019166 (UFMG 2011-1); KJ019167 (UFMG 2011-2); KJ019168 (UFMG 2011-3); KJ019169 (UFMG 2012); KJ019170 (MG 70); samples from other countries with the following accession numbers were used: HQ143383 (MG F USA); JQ770172 (MG S6); KC247865 (MG 6-85); JN935873 (MG PG31); KC247863 (MG USA-R-CK60); and KC247864 (MG TS-11). The IGSR isolate and reference sequences were aligned using Clustal-W, and a dendrogram was constructed using the neighbor-joining method with 1000-bootstrap replicates. Phylogenetic analyses were conducted using the MEGA version 6 software program (Tamura et al., 2013).

\section{RESULTS AND DISCUSSION}

It was obtained 22 isolates, being 11 isolates originated from the trachea, five from the ovary and five from shell gland. The isolates were recovered from seven different flocks in São Paulo, Rio de Janeiro and Espírito Santo (Table 1).

A pairwise analysis carried out to compare the nucleotide sequences allowed the identification of species with $99 \%$ to $100 \%$ homologies to previously characterize sequences on GenBank®. Nonpathogenic mycoplasmas were isolated from three flocks: one from São Paulo and two from Rio de Janeiro. In Flock 2, M. pullorum was isolated from four hens and from all sampling sites (trachea, shell gland and ovary). In addition, M. gallinaceum was found in the shell gland 
of one bird from Flock 2 . The only mycoplasma isolated from Flocks 4 and 5 was $M$. gallinaceum (Table 1). These species, although not considered pathogenic, were able to colonize different parts of the hen. The interaction of M. gallinaceum with MS to exacerbate synovitis has been shown (Yagihashi et al., 1993). Also, the synergistic effect of $M$. gallinaceum with MS was related to a higher prevalence of Infectious Coryza (Gomes, 2013). Evidence that $M$. pullorum and $M$. gallinarum can act as pathogens has been previously reported (Moalic et al., 1997; Silva et al., 2014), but the interactions of these species with MS or MG have not been studied.

Table 1 - The avian mycoplasma isolates used in the present study, Brazilian state of origin, flock identification, site sampled in the bird, species identified, identification of the sample in the laboratory and GenBank accession number of the sequences obtained.

\begin{tabular}{|c|c|c|c|c|c|c|}
\hline Flock location (State) & Flock ID & Hen number & Sampling site & Species & Sample ID & GenBank accession number \\
\hline \multirow{11}{*}{ São Paulo } & Flock 1 & 2 & Trachea & M. gallisepticum & LSA UFF 001 & KT824804 \\
\hline & Flock 2 & 2 & Trachea & M. pullorum & LSA UFF 002 & KT824805 \\
\hline & Flock 2 & 2 & Shell gland & M. gallinaceum & LSA UFF 003 & KT824806 \\
\hline & Flock 2 & 2 & Ovary & M. pullorum & LSA UFF 004 & KT824807 \\
\hline & Flock 2 & 3 & Trachea & M. pullorum & LSA UFF 005 & KT824808 \\
\hline & Flock 2 & 4 & Trachea & M. pullorum & LSA UFF 006 & KT824809 \\
\hline & Flock 2 & 4 & Ovary & M. pullorum & LSA UFF 007 & KT824810 \\
\hline & Flock 2 & 5 & Shell gland & M. pullorum & LSA UFF 008 & KT824811 \\
\hline & Flock 2 & 5 & Ovary & M. pullorum & LSA UFF 009 & KT824812 \\
\hline & Flock 3 & 1 & Trachea & M. gallisepticum & LSA UFF 010 & KT824813 \\
\hline & Flock 3 & 4 & Trachea & M. gallisepticum & LSA UFF 011 & KT824814 \\
\hline \multirow{3}{*}{ Rio de Janeiro } & Flock 4 & 4 & Trachea & M. gallinaceum & LSA UFF 012 & KT824815 \\
\hline & Flock 5 & 1 & Trachea & M. gallinaceum & LSA UFF 013 & KT824816 \\
\hline & Flock 5 & 2 & Trachea & M. gallinaceum & LSA UFF 014 & KT824817 \\
\hline \multirow{7}{*}{ Espírito Santo } & Flock 6 & 1 & Shell gland & M. gallisepticum & LSA UFF 015 & KT824818 \\
\hline & Flock 6 & 1 & Ovary & M. gallisepticum & LSA UFF 016 & KT824819 \\
\hline & Flock 6 & 3 & Ovary & M. gallisepticum & LSA UFF 017 & KT824820 \\
\hline & Flock 6 & 5 & Shell gland & M. gallisepticum & LSA UFF 018 & KT824821 \\
\hline & Flock 7 & 1 & Trachea & M. gallisepticum & LSA UFF 019 & KT824822 \\
\hline & Flock 7 & 2 & Trachea & M. gallisepticum & LSA UFF 020 & KT824823 \\
\hline & Flock 7 & 2 & Shell gland & M. gallisepticum & LSA UFF 021 & KT824803 \\
\hline
\end{tabular}

All other 10 isolates were identified as MG and were obtained from two flocks in São Paulo and two flocks in Espírito Santo. All isolates from Espírito Santo flocks clustered together with UFMG2012 and MG F vaccine strain, suggesting recovery of the vaccine strain.

The samples isolated from Flock 3 were similar to MG 56 but were also closely related to MG 70 vaccine strain, developed in Brazil, which was used in that flock. The sample isolated from Flock 1 was similar to MG 6/85 vaccine strain, despite the use of the MG 70 vaccine strain in that flock (Figure 1). This could be due to contamination from other flocks that had received the MG 6/85 vaccine. Isolates from different States were included in different clusters (Figure 1), implying a spatial distribution. Figure 2 shows the nucleotide differences among the strains examined in this work.

Although avian mycoplasmosis has special importance in the Brazilian national poultry health program, just few studies were carried to estimate prevalence of MG and MS in commercial layer hen flocks. Due to regular vaccination of the flocks, wild type MG prevalence is relatively low, not found using

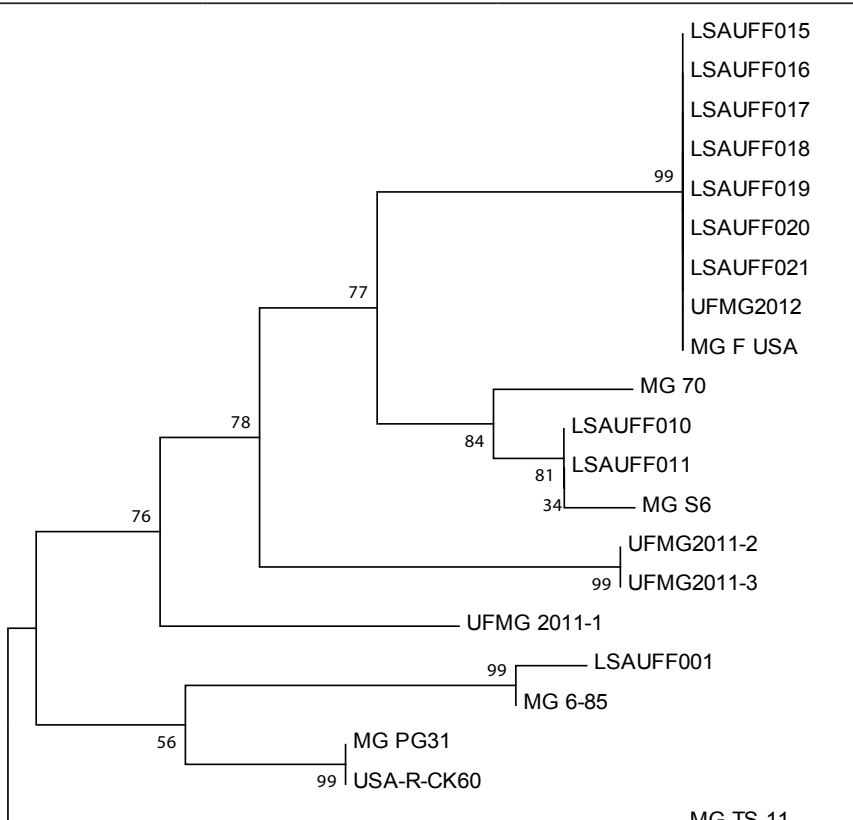

MG TS-11

Figure 1 - Dendrogram of the M. gallisepticum isolates from Brazil, with vaccine and reference strains, constructed by Clustal-W alignment of the IGSR sequences by the neighbor-joining method with 1000-bootstrap replicates using the MEGA 6.0 software program (http://www.megasoftware.net). 
Santos FF, Li J, Brandão MDM,

Machado LS, Soares NM,

Nascimento ER, Khan M, Pereira VLA
Characterization and Differentiation of Chicken Mycoplasma Isolates Using 16S-23S Intergenic Spacer Region Sequencing

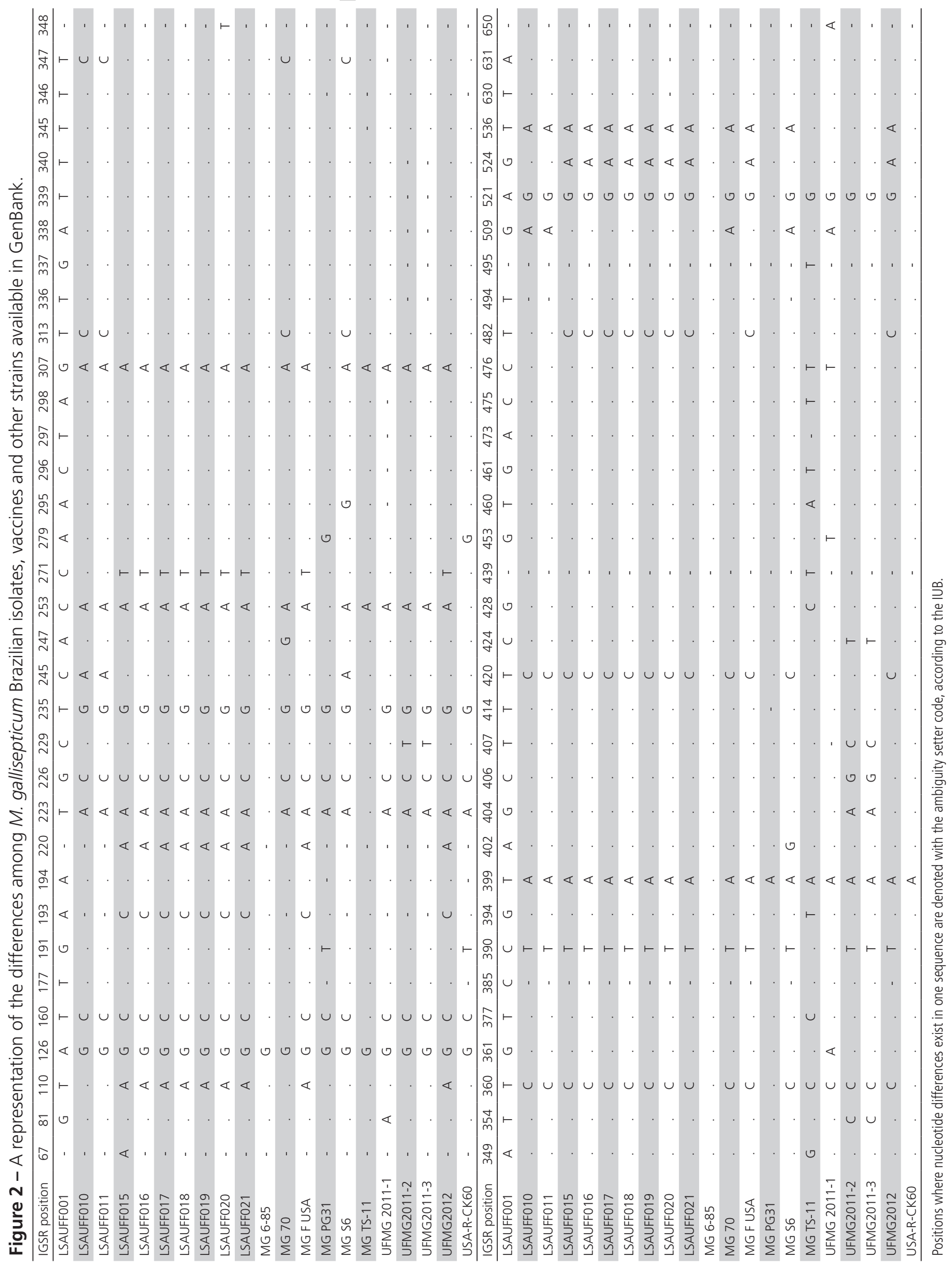


Santos FF, Li J, Brandão MDM,

Machado LS, Soares NM,

Nascimento ER, Khan M, Pereira VLA
Characterization and Differentiation of Chicken Mycoplasma Isolates Using 16S-23S Intergenic Spacer Region Sequencing
PCR by Buim et al. (2009), Mettifogo et al. (2013) and Barros et al. (2014), 5\% (Teixeira et al., 2015) and isolated from $2,67 \%$ of the flocks by Santos (2015). On the other hand, since flocks are not vaccinated for MS in Brazil, prevalence is estimated to be very high, with 79,31\% (Buim et al., 2009), 68\% (Mettifogo et al., 2013), 83,33\% (Barros et al., 2014), 45\% (Teixeira et al., 2015) and 93,34\% (Santos, 2015). However, isolation of pathogenic mycoplasmas may be difficulted by rapid growth of commensal strains, such as $M$. gallinarum and $M$. gallinaceum (Kleven, 2008). Thus, rapid identification of isolates is desirable for diagnostic purposes.

Considering the laborious and time-consuming work of biochemical and serological species confirmation tests (immunoperoxidase/immunofluorescence and growth inhibition) and the difficulty of performing specific PCR for the 23 avian mycoplasma species, the 16S-23S rDNA IGSR sequencing was shown to be a good alternative method to identify isolated strains species, providing fast and reliable results at a relatively low cost. The results were also satisfactory for the SLST of MG isolates, yielding in this work clusters related to the origin of the strains.

The authors thank FAPERJ for the study funding and the first author thanks CNPq for the doctoral scholarship and CAPES for sandwich program support, BEX 18862/12-8.

\section{REFERENCES}

Barros MR, Nascimento ER, Silva JSA, Pinheiro Júnior JW, Santos SB, Machado LS, Silva RCF, Mota RA. Occurrence of Mycoplasma synoviae on commercial poultry farms of Pernambuco, Brazil. Pesquisa Veterinária Brasileira 2014;34(10):953-956.

Buim MR, Mettifogo E, Timenetsky J, Kleven S, Ferreira AJP. Epidemiological survey on Mycoplasma gallisepticum and M. synoviae by multiplex PCR in commercial poultry. Pesquisa Veterinária Brasileira 2009:29(7):552556.

Couto RM, Braga JFV, Gomes SYM, Resende M, Martins NRS, Ecco R. Natural concurrent infections associated with infectious laryngotracheitis in layer chickens. The Journal of Applied Poultry Research 2015; 25(1):113-128.

Ferguson NM, Hepp H, Sun S, Ikuta N, Levisohn S, Kleven SH, García M. Use of molecular diversity of Mycoplasma gallisepticum by gene-targeted sequencing (GTS) and random amplified polymorphic DNA (RAPD) analysis for epidemiological studies. Microbiology 2005;151:18831893.

Fraga AP, Vargas T, Ikuta N, Fonseca ASK, Celmer AJ, Marques EK, Lunge VR. A Multiplex real-time PCR for detection of Mycoplasma gallisepticum and Mycoplasma synoviae in clinical samples from Brazilian commercial poultry flocks. Brazilian Journal of Microbiology 2013;44(2):505-510.

Frey $\mathrm{ML}$, Hanson RP, Anderson DP. A medium for the isolation of avian mycoplasmas. American Journal of Veterinary Research $1968 ; 29(11): 2163-2171$
Ganapathy K, Jones RC, Bradbury JM. Pathogenicity of in vivo-passaged Mycoplasma imitans in turkey poults in single infection and in dual infection with rhinotracheitis virus. Avian Pathology 1998;27(1):80-89.

García M, Ikuta N, Levisohn S, Kleven SH. Evaluation and comparison of various PCR methods for detection of Mycoplasma gallisepticum infection in chickens. Avian Diseases 2005;49(1):125-132.

Gomes AM. Caracterização molecular de Mycoplasma da avicultura industrial dos estados de Minas Gerais e Espírito Santo [thesis]. Belo Horizonte (MG): Universidade Federal de Minas Gerais; 2013.

Hong Y, García M, Leiting L, Bencina D, Dufour-Zavala L, Zavala G, Kleven SH. Specific detection and typing of Mycoplasma synoviae strains in poultry with PCR and DNA sequence analysis targeting the hemagglutinin encoding gene v/hA. Avian Diseases 2004;48(3):606-616.

Kleven SH, Eidson CS, Fletcher OJ. Airsacculitis induced in broilers with a combination of Mycoplasma gallinarum and respiratory viruses. Avian Diseases 1978;22(4):707-716

Kleven SH. Micoplasmosis. In: Saif YM. Diseases of poultry. 12 th ed. Ames, IA: Blackwell publishing; 2008. p.805-864

Lauerman LH. Mycoplasma PCR Assays: Nucleic Acid Amplifications Assays for diagnosis of animal diseases. Alabama: Department of Agriculture and Industries; 1998. 150p.

Mettifogo E, Buzinhani M, Buim MR, Timenetsky J, Ferreira AJP. Evaluation of a PCR multiplex for detection and differentiation of Mycoplasma synoviae, M. gallisepticum, and M. gallisepticum strain F-vaccine. Pesquisa Veterinária Brasileira 2015;35(1):13-18.

Moalic PY, Kempf I, Gesbert F, Laigret F. Identification of two pathogenic mycoplasmas as strains of Mycoplasma pullorum. International Journal of Systematic Bacteriology 1997;47(1):171-174.

Nascimento ER, Pereira VLA, Nascimento MGF, Barreto ML. Avian mycoplasmosis update. Brazilian Journal of Poultry Science 2005;7(1):1-9

Nascimento ER, Pereira VLA. Micoplasmoses. In: Berchieri Jr. A, Silva EN, Di Fabio J, Sesti L, Zuanaze MAF. Doenças das aves. 2 ed. Campinas, SP: FACTA; 2009. p.485-502

Nascimento ER, Yamamoto R, Herrick KR, Tait RC. Polymerase Chain Reaction for detection of Mycoplasma gallisepticum. Avian Diseases 1991;35(1):62-69

National Center for Biotechnology Information, National Library of Medicine. 2017. GenBank- Nucleotide BLAST [cited 2017 Sept]. Available from: http://www.ncbi.nlm.nih.gov/genbank/.

Ramírez AS, Naylor CJ, Pitcher DG, Bradbury JM. High inter-species and low intra-species variation in 16S-23S rDNA spacer sequences of pathogenic avian mycoplasmas offers potential use as a diagnostic tool. Veterinary Microbiology 2008;128(3-4):279-287.

Raviv Z, Callison S, Ferguson-Noel N, Laibinis V, Wooten R, Kleven SH. The Mycoplasma gallisepticum 16S-23S rRNA intergenic spacer region sequence as a novel tool for epizootiological studies. Avian Diseases 2007:51(2):555-560.

Sambrook J, Fritsch EF. Molecular Cloning: A Laboratory Manual. 2nded New York: Cold Spring Laboratory; 1989. 1659 p.

Santos FF. Micoplasmose em poedeiras, caracterização genotípica de isolados e Mycoplasma synoviae como fator de risco na qualidade de ovos comerciais no Sudeste do Brasil [thesis]. Niterói (RJ): Universidade Federal Fluminense; 2015

Silva CC, Brandão MDM, Nascimento ER, Almeida JF, Abreu DLC, Barreto ML, Soares MV, Machado LS, Pereira VLA. Mycoplasma gallinarum in laying hens with respiratory disease. Brazilian Journal of Veterinary Medicine 2014:36(4):347-350. 
Tamura K, Stecher G, Peterson D, Filipski A, Kumar S. MEGA6: Molecular Evolutionary Genetics Analysis version 6.0. Molecular biology and evolution 2013;30:2725-2729.

Teixeira VCM, Baptista DQ, Carlos FC, Menezes WR, José DS, Barreto ML, Abreu DLC, Pereira VLA, Nascimento ER. Epidemiological situation of avian mycoplamosis in the State of Rio de Janeiro, Brazil. Revista Brasileira de Medicina Veterinária 2015;37(4):379-385.
Wang H, Fadl AA, Khan Ml. Multiplex PCR for avian pathogenic mycoplasmas. Molecular and Cellular Probes 1997;11(3):211-216.

Yagihashi T, Nunoya T, Otaki Y. Effects of dual infection of chickens with Mycoplasma synoviae and Mycoplasma gallinaceum or Infectious Bursal Disease virus on infectious synovitis. Japanese Journal of Veterinary Science 1993;45(4):529-532 